\title{
Effects of Fines on Undrained Behaviour of Sands
}

\author{
Misko Cubrinovski ${ }^{1}$ and Sean Rees ${ }^{2}$ \\ ${ }^{1}$ Associate Professor, Department of Civil and Natural Resources Engineering, University of \\ Canterbury, New Zealand; misko.cubrinovski@canterbury.ac.nz \\ ${ }^{2}$ PhD Candidate, Department of Civil and Natural Resources Engineering, University of Canterbury, \\ New Zealand; sdr40@student.canterbury.ac.nz
}

\begin{abstract}
A series of monotonic and cyclic triaxial tests were performed on a sand with fines sourced from Christchurch, New Zealand. The sand was sieved and then mixed to give three soils with different fines contents. The undrained tests were used to examine the effects of fines on the strain softening behaviour under monotonic loading and liquefaction resistance in cyclic loading. Two reference states were used as a basis for evaluation of the effects of fines: the relative density and the steady state line within the state-concept framework for sand characterization. The addition of fines to the sand base caused downward movement of the steady state line in the $D_{r}-p^{\prime}$ plane (e-p' plane), and this effectively increased the potential for strain softening or flow deformation. Samples prepared at an identical relative density showed decreasing cyclic strength with increasing fines content. Conversely, samples at an identical initial state relative to the steady state line showed increasing cyclic strength with the fines content.
\end{abstract}

\section{INTRODUCTION}

Case histories from strong earthquakes and laboratory studies show clearly that fines have significant influence on both monotonic and cyclic undrained behaviour of sands (Lade and Yamamuro, 1997; Thevanayagam, 1998; Polito and Martin, 2001). These effects are particularly relevant when evaluating the potential for strain softening or flow deformation during monotonic loading and liquefaction resistance in cyclic loading. When comparing the liquefaction resistance of fines-containing sand with that of a clean sand, one encounters the problem of a lack of proper basis for comparison. For example, in the conventional procedure for liquefaction evaluation based on the penetration resistance (Youd and Idriss, 1998), finescontaining sands show greater liquefaction resistance as compared to clean sands. In these criteria, however, the penetration resistance, e.g. normalized SPT blow count $N_{l}$, is used as a basis for comparison. Since the penetration resistance is affected by the grain size and fines content, these criteria do not show only the effects of fines on the liquefaction resistance but rather they depict the combined effects of fines on 

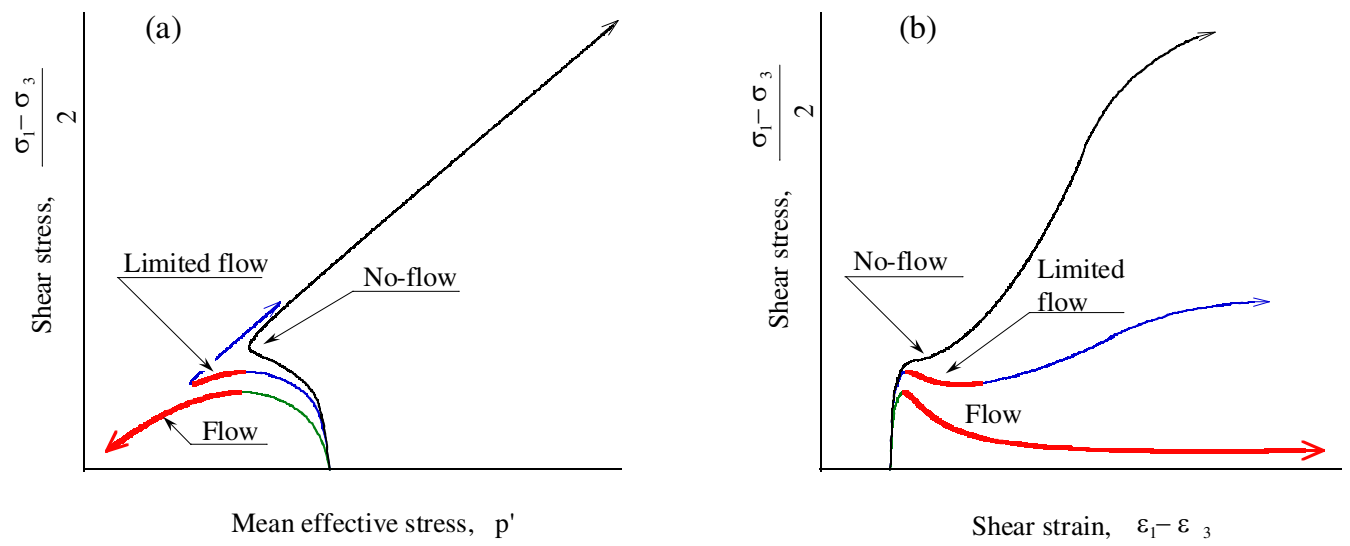

FIG. 1. Undrained behaviour of sand in monotonic tests

both penetration resistance and liquefaction resistance. Thus, it is not straightforward from these charts whether the fines per se increase the liquefaction resistance or not. In order to investigate the effects of fines in more detail, a series of undrained triaxial tests were conducted on natural sands recovered from a site in Christchurch, New Zealand. In the interpretation of the effects of fines on undrained behaviour both the relative density of the soil and the initial state of the soil relative to its steady state line (state-concept interpretation) were used as a basis for comparison.

\section{EFFECTS OF FINES ON UNDRAINED MONOTONIC BEHAVIOUR}

\section{Background}

Three types of response characterize undrained behaviour of sands under monotonic shearing, as outlined in Figure 1. Very loose sand shows fully contractive behaviour and strain softening until the steady state or critical state is reached at large strains. The strain-softening phase of the response resembles flow-type behaviour and therefore it is often referred to as flow or flow deformation. If the density of the sand is somewhat higher, then the strain softening takes place over a limited range, and limited flow occurs followed by strain hardening and steady state of deformation. Finally, in the case of medium dense and dense sands, a strain-hardening response associated with strong dilation towards the steady state is observed.

The undrained behaviour of a given sand changes within the three types of response outlined in Figure 1 and shows different degrees of strain softening and strain hardening depending upon the density of the sand and confining stress at the initial state, prior to shearing. It is possible, therefore, to distinguish between initial density-stress states that are associated with strain-softening behaviour (flow deformation) and those entirely exhibiting strain-hardening behaviour in monotonic undrained loading. In this context, Ishihara (1993) defined a so-called initial dividing line (ID-line) that marks the boundary between flow and no-flow conditions in the $e$ $p^{\prime}$ diagram (void ratio-mean effective stress diagram). As illustrated in Figure 2, samples lying above the ID-line are contractive and exhibit flow-type behaviour while all of the initial density-stress combinations lying below the ID-line exhibit strain-hardening behaviour upon monotonic shearing under undrained conditions. 


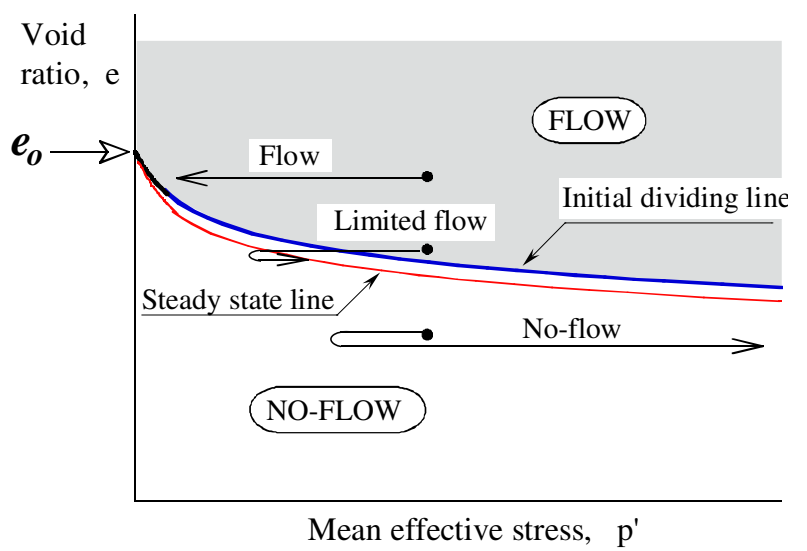

FIG. 2. Characterization of monotonic undrained behaviour based on state concept

This illustrates the essence of the state-concept interpretation of sand behaviour where a particular type of behaviour is associated with the initial $e-p^{\prime}$ state of the soil relative to a reference state.

As depicted in Figure 2, the projection of the steady state line in the $e-p^{\prime}$ plane is relatively close to the initial dividing line, and therefore, it could be used as its approximation when identifying whether the sand behaviour upon monotonic undrained shearing is of strain-softening or strain-hardening type. Two features of the steady state line make this line a particularly suitable reference state. Firstly, the steady state line is unique for a given sand, and therefore, the position of the steady state line is uniquely defined in the $e-p^{\prime}$ plane. Secondly, any soil sample subjected to monotonic shearing will eventually reach the steady state of deformation; in other words, the ultimate $e-p^{\prime}$ state will end up on the steady state line irrespective of the initial $e-p^{\prime}$ state of the soil. Hence, the ultimate level of dilation/contraction or excess pore water pressure development in monotonic undrained shearing is practically defined by the initial $e-p^{\prime}$ state of the soil relative to the steady state line. All initial states above the steady state line will show contractive behaviour or positive excess pore water pressure. The contractive tendency or excess pore pressure level will increase with the distance from the steady state line. Note that initial states with a void ratio greater than $e_{o}$ will end up at $p^{\prime}=0$ and exhibit zero steady state strength upon monotonic undrained loading.

The position and slope of the steady state line of sandy soils are affected by a number of factors including the grain-size characteristics, fines content and grain shape of sands. Figure 3 summarizes the effects of grain-size composition and fines content on the steady state line of sandy soils. Here, the circular symbols show published data on 52 sandy soils obtained from triaxial compression tests on reconstituted samples of clean sands and sands with non-plastic fines (Cubrinovski and Ishihara, 2000). The figure also includes recently summarized data by Jefferies and Been (2006) and results for the three soils tested in this study. Note that $D_{r o}$ indicates the relative density corresponding to $e_{o}$ (see Figure 2) and hence defines the threshold relative density below which soils exhibit a zero steady state strength. Figure 3 shows that the position of the steady state line in the $e-p^{\prime}$ plot or $D_{r}-p^{\prime}$ plot is 

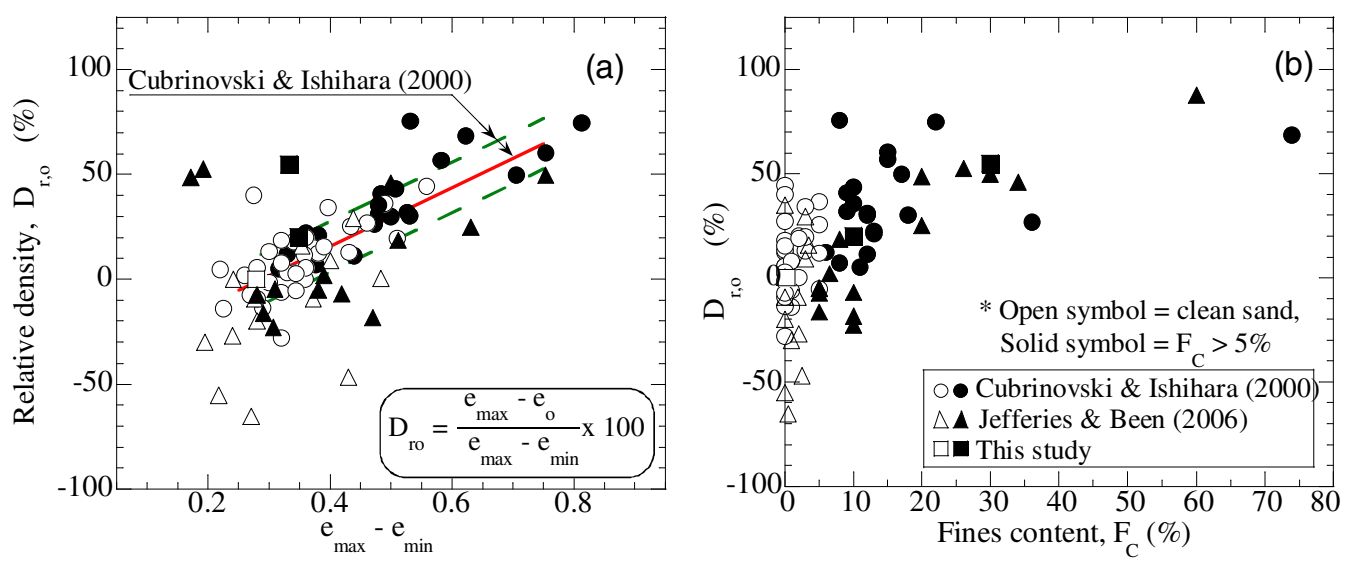

FIG. 3. Position of the steady state line of sandy soils as a function of: (a) Void ratio range, $\left(e_{\max }-e_{\min }\right) ;(b)$ Fines content, $F_{C}$

related to the grain-size composition, as represented by the void ratio range $\left(e_{\max }{ }^{-}\right.$ $\left.e_{\min }\right)$, and fines content, $F_{C}$. As the fines content or $\left(e_{\max }-e_{\min }\right)$ increases, the steady state shifts downwards in the $e-p^{\prime}$ plot or the relative density $D_{r o}$ corresponding to $e_{o}$, defined in Figure 2, increases. This implies that, at a given relative density, loose samples containing fines are more contractive and show greater potential for strain softening than clean sands. This feature of the undrained behaviour of sands was further investigated by testing samples of Christchurch soils with different fines content using conventional triaxial compression tests.

\section{Materials Tested}

Three soils were tested in this study all based on a host sandy soil obtained from a single layer at the Fitzgerald Bridge Avenue site in Christchurch, New Zealand. We will call the host material as well as the soils derived from it Fitzgerald Bridge Mixture (FBM) and will distinguish between them based on the fines content, as follows. The host soil FBM-10 was created by mixing "undisturbed" samples obtained from the Fitzgerald Avenue Bridge site. The initial soil mixture created in this way was a silty sand containing approximately $10 \%$ fines by weight (FBM-10), with the fines determined to be non-plastic. This material was dry-sieved after testing to isolate the clean-sand base and create the second material that happened to have $1 \%$ fines by weight (FBM-1). Finally, the third soil was produced by reintroducing the fines to the clean-sand base, and creating a silty sand with approximately $30 \%$ fines by weight (FBM-30). Material properties of the tested soils are summarised in Table 1 while their grain-size curves are shown in Figure 4 . Note that $e_{\max }$ and $e_{\min }$

Table 1. Properties of the tested soils

\begin{tabular}{|c|c|c|c|c|c|}
\hline Material & $\mathbf{F}_{\mathbf{C}}(\boldsymbol{\%})$ & $\mathbf{G}_{\mathbf{s}}$ & $\mathbf{e}_{\max }$ & $\mathbf{e}_{\min }$ & $\mathbf{e}_{\max }-\mathbf{e}_{\min }$ \\
\hline FBM-1 & 1 & - & 0.907 & 0.628 & 0.279 \\
\hline FBM-10 & 10 & 2.664 & 0.945 & 0.597 & 0.348 \\
\hline FBM-30 & 30 & - & 0.860 & 0.527 & 0.333 \\
\hline
\end{tabular}




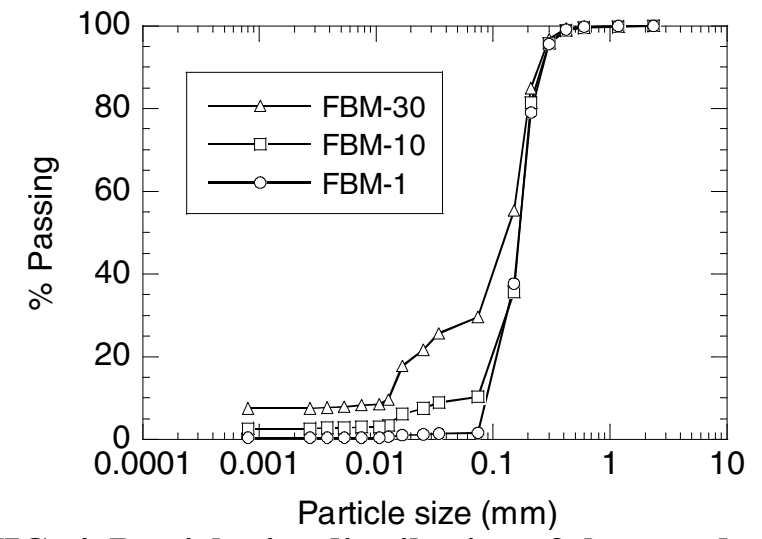

FIG. 4. Particle size distribution of the tested soils

were obtained for all soils using the British standard procedures for minimum and maximum densities of sands (BSI, 2002). Whereas one should be cautious when applying these procedures to soils with relatively high fines contents, Cubrinovski and Ishihara (2002) presented evidence based on 300 natural soils that the procedures stipulated by the Japanese Geotechnical Society for clean sands (JGS, 2000) provide reasonably consistent $e_{\max }$ and $e_{\min }$ values for sands with a fines content of up to $30 \%$.

Each of the three soils required re-use during the monotonic and cyclic triaxial testing. This was due to the limited amount of material available. The tested soil was dried overnight at $104^{\circ} \mathrm{C}$ and then gently ground to allow a return to a homogenous material. This soil was placed in a separate container and only re-used once the original material mixture had been exhausted. An effort was made during these steps to retain as much material (particularly fines) as possible. Particle size distributions taken of the re-used material varied insignificantly from the original grain-size curves shown in Figure 4.

\section{Results from Monotonic Tests}

In total, 28 undrained monotonic tests in triaxial compression were performed on the three materials created from the Fitzgerald Bridge soils. All specimens were prepared using the moist-tamping method by firstly preparing the sand to a moisture content of approximately 9\%, placing the soil in 6 equal layers, and applying an appropriate amount of tamping for the target specimen density. The specimens had conventional dimensions of approximately $50 \mathrm{~mm}$ in diameter and $100 \mathrm{~mm}$ in height. All specimens had $\mathrm{CO}_{2}$ percolated through them before saturation for varying amounts of time, with the amount of time increasing with the fines content. The samples were isotropically consolidated to an initial mean effective stress of $100 \mathrm{kPa}$, except for two tests in which $p^{\prime}=200 \mathrm{kPa}$ was used. The tests were conducted in a strain-controlled manner at an axial strain rate of $0.3 \% / \mathrm{min}$.

Figure 5 shows stress-strain curves and effective stress paths for each of the three soils tested. In this case, all three specimens exhibited either limited flow or flow deformation. The stress-strain relationships shown in Figure 5(a) give good indication of how fines can affect undrained behaviour of sand. All specimens peak at approximately the same stress level, around $80 \mathrm{kPa}$ to $90 \mathrm{kPa}$, but the steady state 

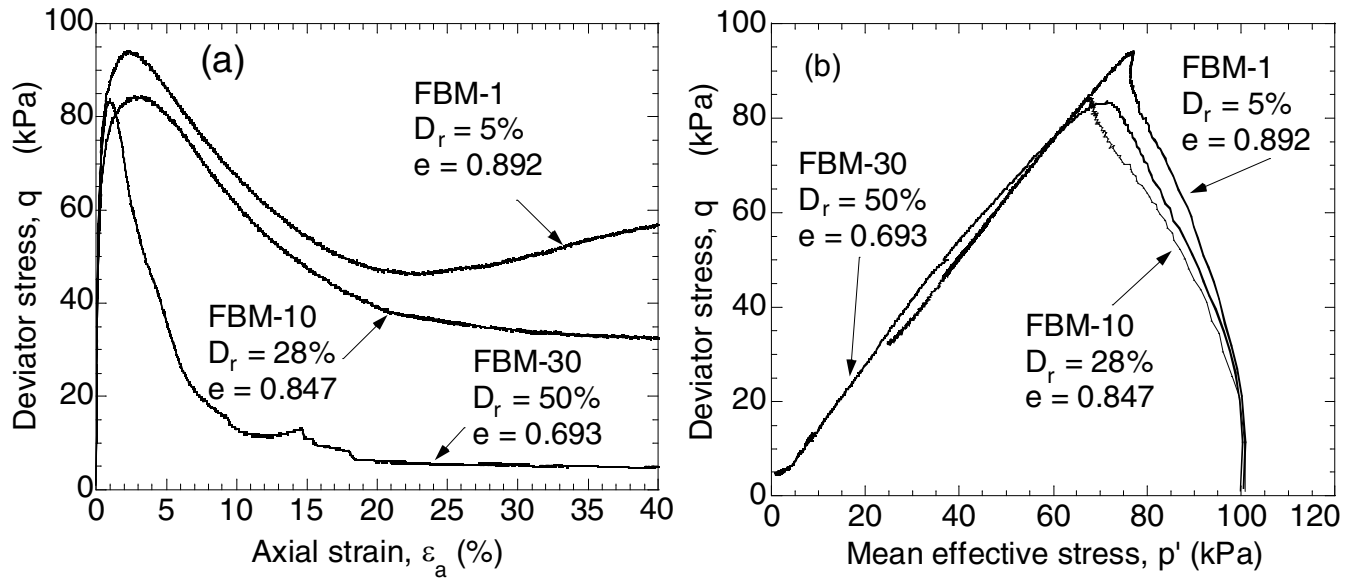

FIG. 5. Stress-strain curves and effective stress paths observed in monotonic undrained tests on sands with different fines content

stresses vary significantly. The clean sand mixture (FBM-1) has the highest stress at steady state, being close to $\mathrm{q}=55 \mathrm{kPa}$, whilst having the lowest relative density of $\mathrm{D}_{\mathrm{r}}=5 \%$. The specimen prepared using the FBM-30 mixture has the lowest stress at steady state, with $\mathrm{q}=5 \mathrm{kPa}$, yet is the densest specimen with a relative density of $\mathrm{D}_{\mathrm{r}}=50 \%$. These responses demonstrate that the addition of fines to the clean sand base increased the potential for flow deformation during undrained monotonic loading. The sand with 30\% fines (FBM-30) shows greater drop in the shear stress during the strain softening at a relative density of $D_{r}=50 \%$ than the clean sand (FBM-1) at a relative density of $D_{r}=5 \%$. This result is in agreement with findings from previous studies summarized in Figure 3.

Another way to consider these effects is to depict the position of the steady state line for each of the tested soils in the $e-p^{\prime}$ plot or even more suitably in the $D_{r}-p^{\prime}$ plot, as shown in Figure 6. Here, the steady state condition of a given test is defined by the
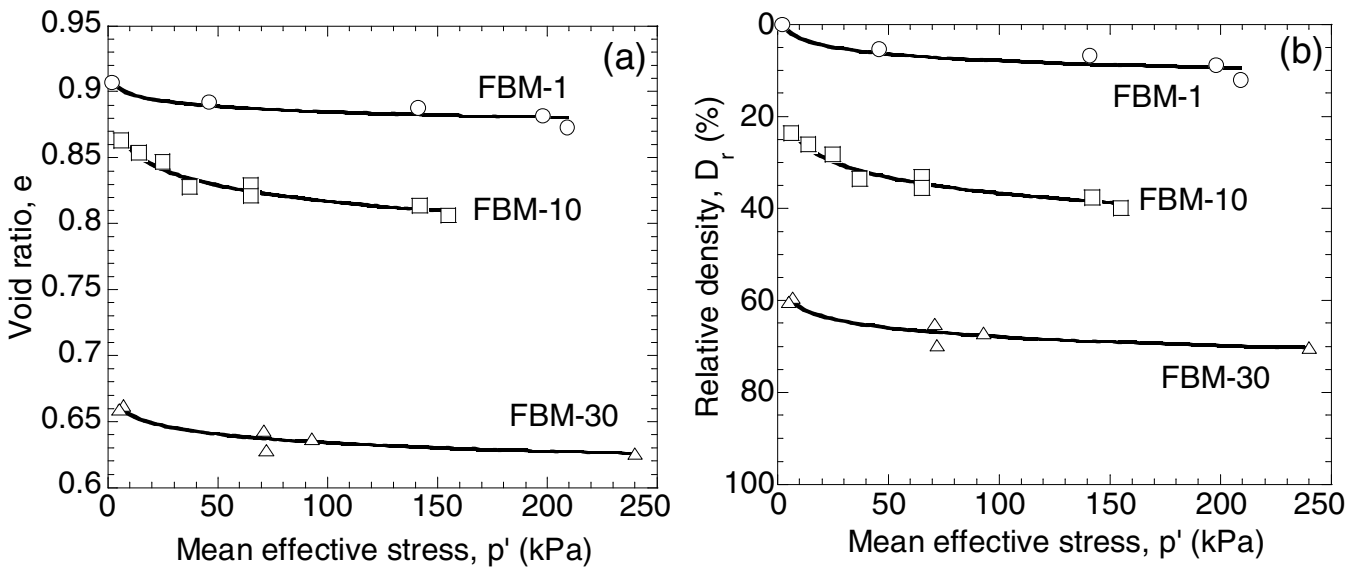

FIG. 6. Effects of fines on the position of the steady-state line: (a) $e-p^{\prime}$ plane; (b) $D_{r}-p^{\prime}$ plane 
state at $40 \%$ strain. The downward shift in the steady state line as the fines content increases can be clearly seen in Figures 6(a) and (b); the steady state line for FBM-1 is at relative densities of $0 \%$ to $10 \%$ while the corresponding relative density for FBM-30 is $60 \%$ to $70 \%$. In view of the state-concept interpretation of sand behaviour introduced previously, the downward shift in the steady-state line with increasing fines content in effect implies that fines tend to increase the flow potential and make the sand more contractive during undrained monotonic loading, at least when the relative density is used as a basis for comparison.

\section{EFFECTS OF FINES ON UNDRAINED CYCLIC BEHAVIOUR}

\section{Results from Cyclic Tests}

In addition to the monotonic tests, undrained cyclic triaxial tests were performed on the three tested soils. In total 43 cyclic tests were conducted including three series of tests on FBM-1, four series of tests on FBM-10 and two series of tests on FBM30. Each of these test series was used to determine the liquefaction resistance curve for a selected relative density of the respective soil. All specimens were prepared using the previously described moist-tamping technique and were isotropically consolidated to an initial mean effective stress of $p^{\prime}=100 \mathrm{kPa}$. Figure 7 shows typical effective stress path and stress-strain response observed in one of the cyclic tests.

For each soil, four or five specimens were prepared at a nearly identical relative density (void ratio), and then the specimens were subjected to cyclic stresses at different cyclic stress ratios (CSR) allowing liquefaction resistance or cyclic strength curves to be generated for each test void ratio (relative density). Liquefaction resistance curves determined in this way are shown in Figure 8 where the cyclic stress ratio is plotted against the number of cycles required to cause $5 \%$ double amplitude strain. As expected, for each soil, the liquefaction resistance increases with the relative density of the soil. The effects of fines on the liquefaction resistance are not apparent in these plots. In order to scrutinize these effects, in what follows the liquefaction resistance of soils FBM-1, FBM-10 and FBM-30 is examined using two reference states: the relative density of the sand and the steady state line respectively.
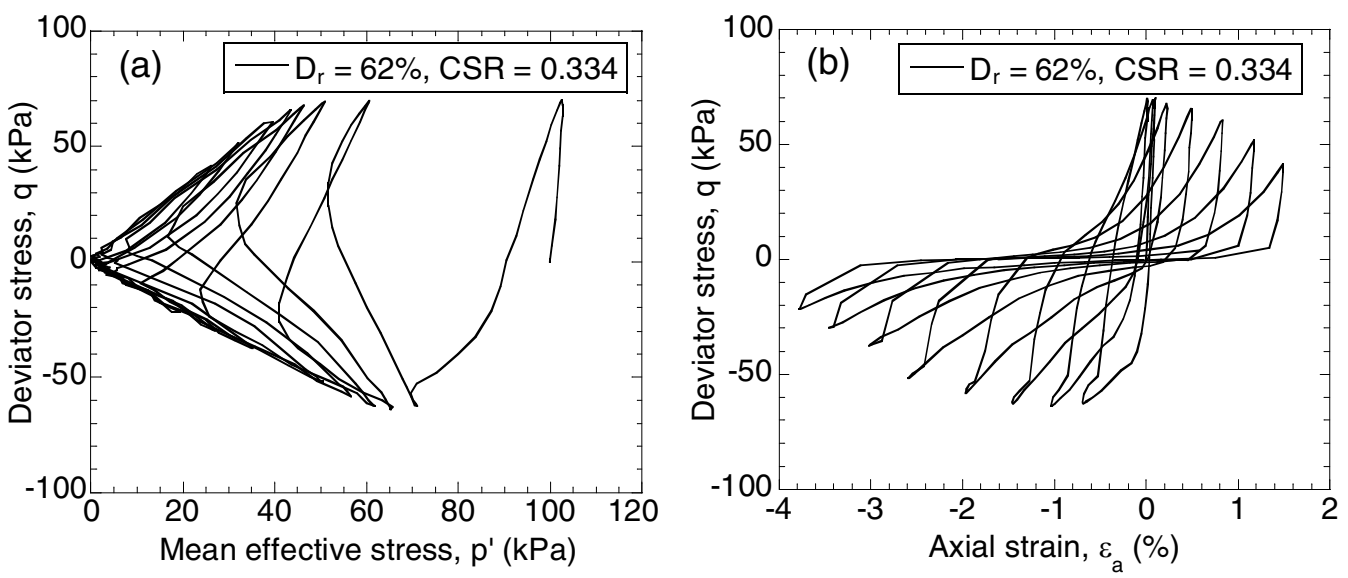

FIG. 7. Stress path and stress-strain curve observed in a cyclic test on FBM-1 

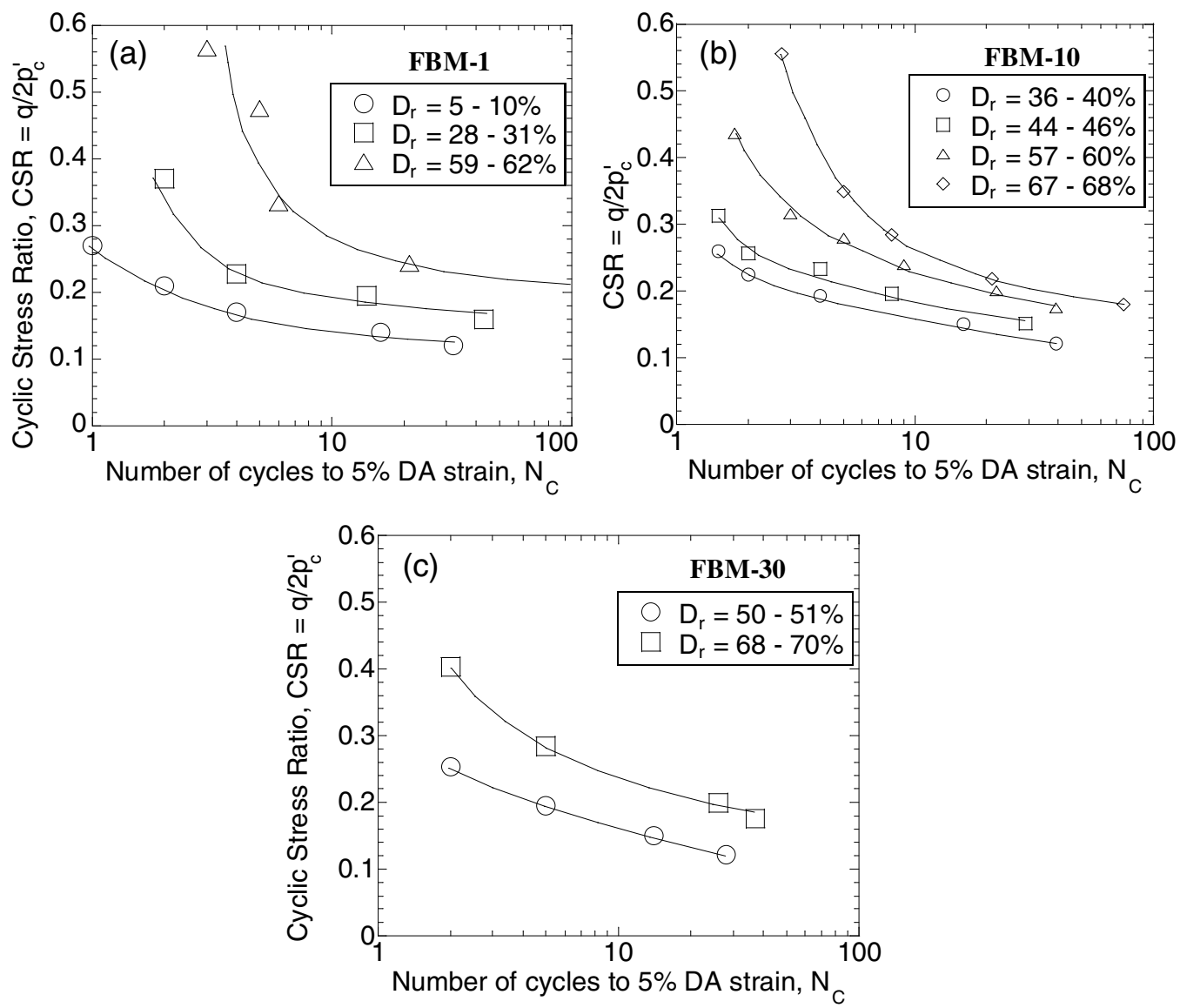

FIG. 8. Liquefaction curves for the tested soils at different relative densities: (a) FBM-1; (b) FBM-10; (c) FBM-30;

The cyclic strength data is re-plotted in Figure 9 where cyclic stress ratios at 5 cycles and 15 cycles, $\mathrm{CSR}_{\mathrm{Nc}=5}$ and $\mathrm{CSR}_{\mathrm{Nc}=15}$ respectively, are plotted against the relative density of the soil. These plots allow comparison of the liquefaction resistance of soils with different fines content, at the same relative density. Clearly, at any relative density within the range considered, the clean sand shows higher cyclic strength than the sand containing $10 \%$ or $30 \%$ fines. In other words, when the relative density is used as a reference for comparison, the liquefaction resistance of FBM soils decreases with increasing fines content.

The state concept approach has already been shown to be useful in describing the undrained monotonic behaviour of sand. Parameters such as the state parameter (Been and Jefferies, 1986; Roscoe and Poorooshasb, 1963) and state index (Ishihara, 1993) quantify the initial state of the soil relative to the steady state line, whilst taking into account combined effects of density and stress on sand behaviour. Therefore, it is interesting to examine how this concept works in describing the undrained cyclic behaviour of sands, and in particular the effects of fines on the liquefaction resistance.

The most straightforward way to assess the suitability of the state concept in 

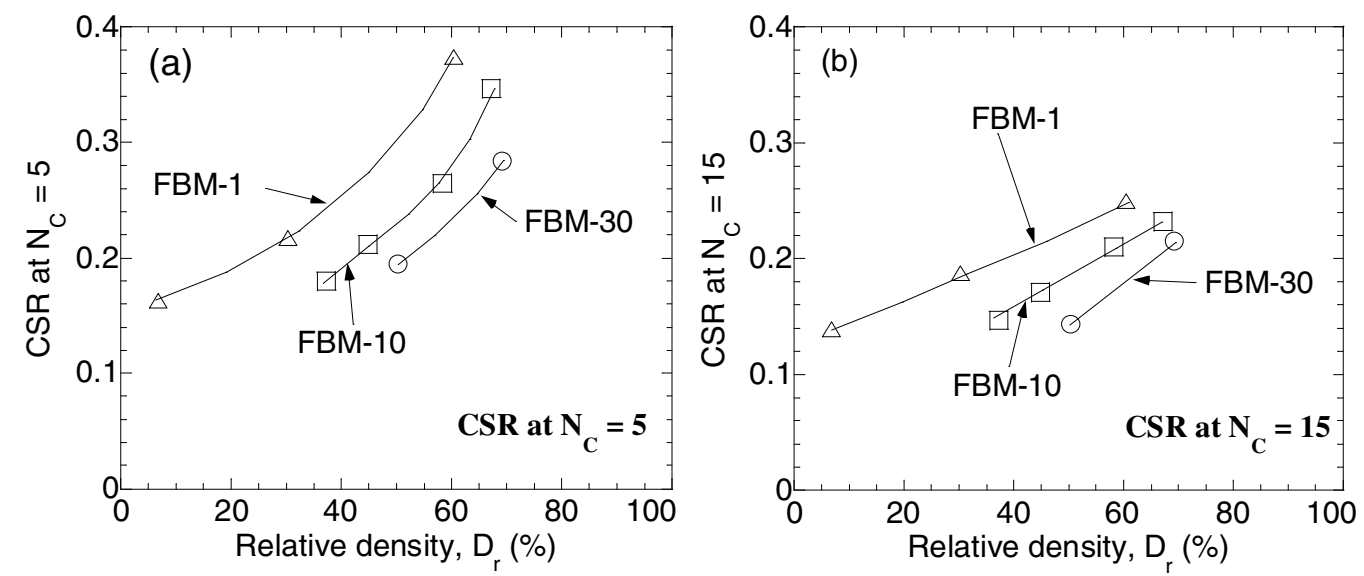

FIG. 9. Cyclic stress ratio required to cause 5\% DA strain in 5 cycles (a) and 15 cycles (b) as a function of relative density

describing undrained cyclic behaviour is to compare the cyclic response for initial states lying on the steady state line itself. Both the state index $\left(I_{s}\right)$ and the state parameter $(\psi)$ have a constant value along the steady state line, $I_{s}=1$ and $\psi=0$ respectively, and this suggests that the monotonic behaviour for all initial states lying along the steady state line should be similar. This is readily apparent for an undrained test because in such a case the initial state prior to shearing and the ultimate state achieved upon monotonic shearing will be identical. In other words, the pore pressure due to the contractive tendency and dilation will be identical when a sample with an initial state at the projection of the steady state line is subjected to undrained monotonic shearing.

Figure 10 shows the cyclic strength curves for the three tested soils, for specimens with initial states on the steady state line. Here, all samples had an initial mean

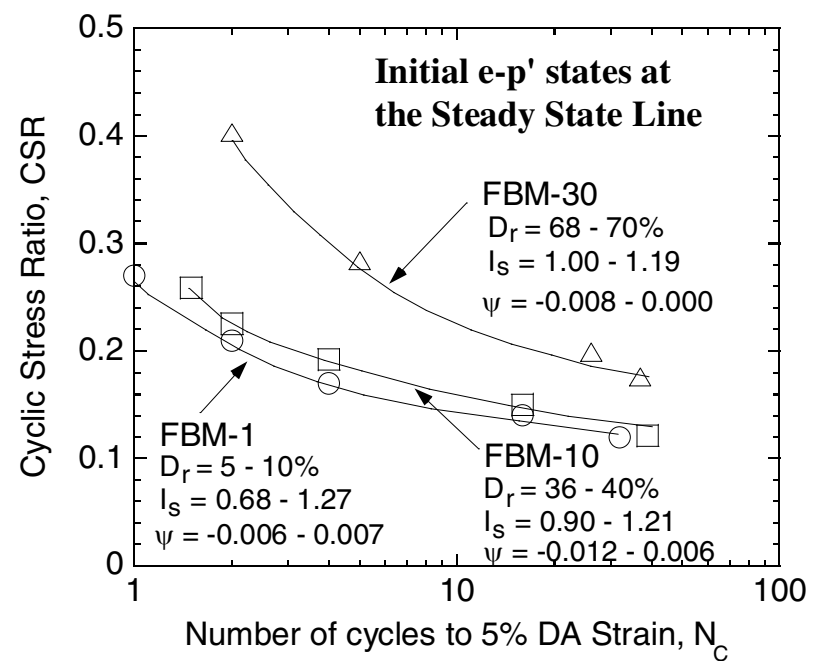

FIG. 10. Cyclic strength curves for specimens with initial states on the steady state line 

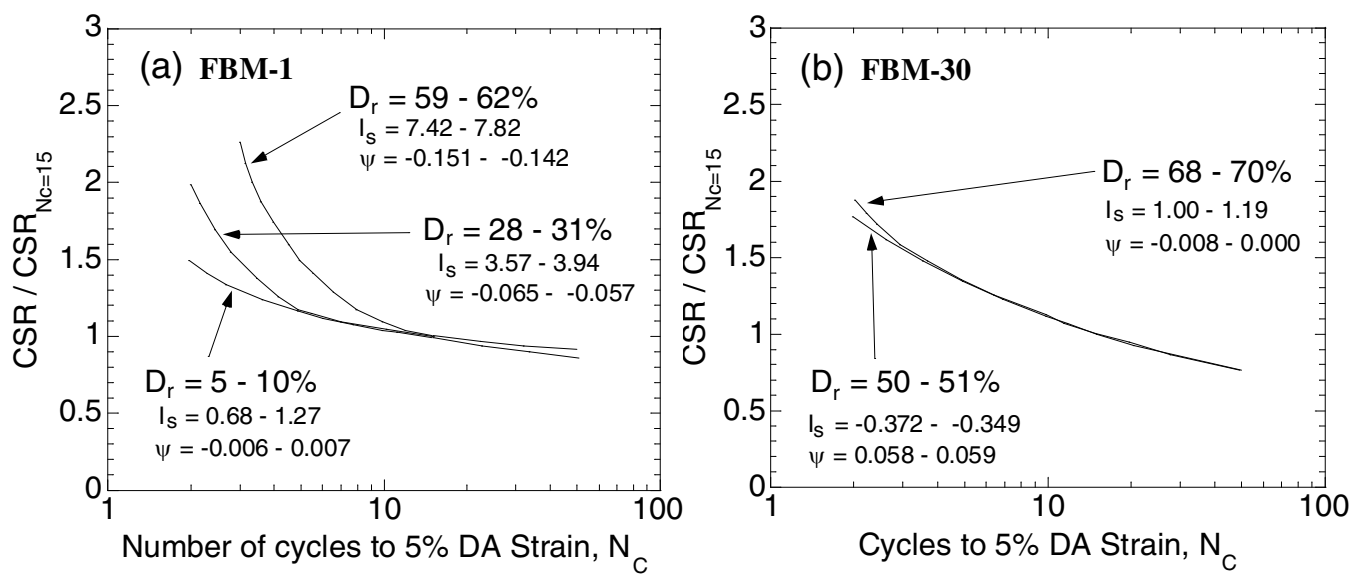

FIG.11. Cyclic liquefaction curves for FBM-1 (a) and FBM-30 (b) normalised by $\mathrm{CSR}_{\mathrm{Nc}=15}$

effective stress of $p^{\prime}=100 \mathrm{kPa}$ and quite different relative density of $D_{r}=5-10 \%$, 36$40 \%$ and $68-70 \%$, for FBM-1, FBM-10 and FBM-30 respectively, in accordance with the position of the steady state line of these soils shown in Figure 6b. Figure 10 shows clear effects of fines on the liquefaction resistance of samples having identical initial states relative to the steady state line. There is a small increase in the cyclic stress ratios for the sand containing 10\% fines (FBM-10) as compared to the clean sand (FBM-1), and furthermore a significant increase in CSR as the fines content reaches 30\% (FBM-30). Clearly, the liquefaction resistance of FBM soils increases with the fines content when initial states on the steady state line or more generally when the state concept is used as a basis for comparison. As the specimens were all prepared using the same technique, effects of fabric are most likely not significant and any differences in fabric would be due to the effects of fines content on fabric.

In order to examine the effects of relative density, state of the soil and fines content on the shape of the liquefaction resistance curve, the cyclic stress ratio was normalized by the CSR at 15 cycles $\left(\mathrm{CSR}_{\mathrm{Nc}=15}\right)$, as shown in Figure 11 for FBM-1 and FBM-30. The clean sand (FBM-1) curves show an increase in the liquefaction resistance with increasing density or corresponding change in the state measure, in the region below 10 cycles. The normalised curves for FBM-10 (not shown) were similar to the FBM-1 curves. In the case of FBM-30, however, the effects of density or state of the soil on the shape of the curve are not pronounced, though one should acknowledge that the range of densities/states considered was relatively small for this soil. Further testing both at low densities high above the steady state line and at high densities well below the steady state line are needed to quantify the effects of fines in this regard.

\section{CONCLUSIONS}

A series of monotonic and cyclic triaxial tests on FBM soils were used to investigate the effects of non-plastic fines on undrained behaviour of sand. The key findings can be summarized as follows: 
(a) The steady state line shifts downwards in the $e-p^{\prime}\left(D_{r}-p^{\prime}\right)$ plot as fines are added to a clean-sand base. This effectively increases the flow potential of the finescontaining soil, as there are more initial states in the $e-p^{\prime}$ plane above the steady state line showing contractive behaviour associated with strain softening.

(b) When the relative density $\left(D_{r}\right)$ is used as a basis for comparison of cyclic behaviour, the cyclic strength decreases with increasing fines content. At a given relative density, the liquefaction resistance of the clean sand (FBM-1) was the highest while the sand with 30\% fines (FBM-30) showed the lowest resistance.

(c) The liquefaction resistance of FBM soils increases with the fines content when initial states on the steady state line or more generally the state concept is used as a basis for comparison.

(d) The shape of the cyclic strength curve of FBM soils is affected by the relative density and initial state of the soil. The extent of these effects, in turn, depends on the fines content.

\section{REFERENCES}

Been, K., and Jefferies, M. G. (1985). "A state parameter for sand." Geotechnique. 35 (2): 99-112.

BSI (2002). BS 1377-4:1990 Methods of tests for soils for civil engineering purposes. Part 4: Compaction-related tests.

Cubrinovski and Ishihara (2000). "Flow potential of sandy soils with different grain compositions," Soils and Foundations, 40 (4): 103-119.

Cubrinovski and Ishihara (2002). "Maximum and minimum void ratio characteristics of sands," Soils and Foundations, 42 (6): 65-78.

Ishihara, K. (1993). "Liquefaction and flow failure during earthquakes." 33-rd Rankine Lecture, Geotechnique. 43 (3): 351-415.

Japanese Geotechnical Society (2000). Test methods for minimum and maximum densities of sands, Soil Testing Standards. (in Japanese).

Jefferies, M. G. and Been, K. (2006). Soil liquefaction: a critical state approach. Taylor\&Francis, New York.

Lade, P.V. and Yamamuro, J. (1997). "Effects of nonplastic fines on static liquefaction of sands." Canadian Geotechnical Journal, 34, 918-928.

Polito, C.P. and Martin II J.R. (2001). "Effects of nonplastic fines on the liquefaction resistance of sands." ASCE Journal of Geotechnical and Geoenvironmental Engineering, 127 (5), 408-415.

Roscoe, K. H., and Poorooshasb, H. B. (1963). "A fundamental principle of similarity in model tests for earth pressure problems." Proceedings of the 2nd Asian Regional Conference on Soil Mechanics, Vol. 1, Tokyo: 134-140.

Thevanayagam, S. (1998). "Effects of fines and confining stress on undrained shear strength of silty sands." ASCE Journal of Geotechnical and Geoenvironmental Engineering, 124 (6), 479-491.

Youd, T.L. and Idriss, I.M. (1998). "Liquefaction resistance of soils: summary report from the 1996 NCEER and 1998 NCEER/NSF Workshops on Evaluation of LiquefactionResistance of Soils " Journal of Getoechnical and Geoenvironmental Engineering, 127 (4): 297-313. 